\title{
MARCEL SCHWOB EM TRADUÇÃO
}

\author{
Claudia Borges de Faveri \\ Universidade Federal de Santa Catarina \\ cbfaveri@gmail.com
}

\begin{abstract}
Resumo: Marcel Schwob (1867-1905) ocupa um lugar singular no contexto da literatura francesa e mundial. Pouco conhecido, mesmo em seu país natal, ele é, no entanto, considerado, por um seleto grupo, como um dos mais importantes escritores do seu tempo. São apenas duas as obras de Schwob traduzidas ao português brasileiro, Vidas imaginárias e $A$ Cruzada das crianças. Este artigo se propõe a apresentar o estado atual das traduções da obra de Marcel Schwob no Brasil, dando início a uma discussão mais aprofundada sobre estas traduções e sobre as principais questões colocadas pela obra de Schwob ao campo dos Estudos da Tradução.
\end{abstract}

Palavras-chave: pesquisa em tradução, Marcel Schwob, tradução ao português.

\begin{abstract}
Marcel Schwob's place in the French and world literature contexts is a very singular one. Barely known, even in his country, yet he is considered, by a select group, as one of the most important writers of the nineteenth century. Only two of his fiction works have been translated into Brazilian Portuguese, Imaginary lives (1896) and The children crusade (1896). This article intends to present the current state of Marcel Schwob's translation works in Brazil and to give birth to a more complete discussion about them and about fundamental questions that Schwob's works propose to the Translation Studies domain.
\end{abstract}

Keywords:research in translation, Marcel Schwob, Portuguese translations.

Adolescente, ele viveu entre os livros da biblioteca Mazarine, guiado por seu tio Léon Cahun, que lhe apresentou Villon, Rabelais e o amor pela filologia. Antes, ainda criança, lera Poe e Mark Twain no original, além de todos os livros de Júlio Verne. Aos 
nove anos, os livros de aventura fizeram florescer sua fértil imaginação e o gosto pelo escrever. É assim, à maneira de suas Vidas imaginárias, que a figura de Marcel Schwob parece emergir de sua breve vida, marcada por uma obra singular, pelo amor aos livros, à aventura e, também, tragicamente, pela doença que o leva aos trinta e sete anos.

Escritor e jornalista, Schwob compõe o essencial de sua obra de ficção em um curto período, entre 1891, quando publica Coeur double e 1896, ano de A Cruzada das crianças e Vidas imaginárias. Entre essas obras, outras três de semelhante calibre: Le roi au masque d'or, Mimes e Le Livre de Monelle. Dos livros acima, apenas dois foram traduzidos ao português, como os títulos indicam, sendo que $A$ Cruzada das crianças, conta com três traduções diferentes.

Mas seu legado não se resume a estes títulos emblemáticos. Schwob foi jornalista, crítico literário e teatral prolífico, e uma influência importante nos círculos literários mais prestigiados de sua época. Provam-no algumas dedicatórias célebres, como a de Valéry em sua Introdução ao método de Leonardo Da Vinci e de Jarry em Ubu rei. Admirado por sua erudição, Schwob se singulariza pela extensão e profundidade de suas leituras, "que vão de Tácito a Whitman" (Goncourt, apud Fabre, 2006, p. 66). Schwob foi também tradutor, traduzindo sobretudo do inglês: Shakespeare, Defoe, Wilde e De Quincey. Thomas Regnier (2006, p. 25) sublinha sua polivalência e erudição:

On n'en finit pas en effet d'énumérer les multiples personnages qui coexistent en Marcel Schwob: le conteur, l'essayiste, le critique littéraire, le chroniqueur de faits divers, mais aussi le traducteur possédant l'anglais comme le grec ancien, le linguiste spécialiste de Villon et du jargon de la Coquille, le bibliophile, et l'on en oublie problablement.

Sua obra é uma mistura sutil de gêneros, onde história e ficção, ensaio, conto e crônica entretecem o maravilhoso, o paradoxal e o 
fantástico. "Le vrai lecteur construit autant que l'auteur: seulement il bâtit entre les lignes" (Schwob, 2002, p. 964) escreve ele em seu último texto, Il libro della mia memoria, o que nos revela algo de sua concepção da criação e, também, um olhar para a literatura que, em sua modernidade, está à frente daquele de seus contemporâneos. Sua Escrita é reescritura, palimpsesto no sentido de Genette (1982), trabalho de criação que multiplica indefinidamente o jogo de reminiscências literárias. Estruturas, ritmos e imagens vêm determinar os contornos de um imaginário pessoal, uma poética que imprime sua marca individual à heterogeneidade da tradição que o inspira. Seus textos, povoados de magos, heréticos e aventureiros, espelhos e máscaras, brincam com o leitor, deixando-lhe falsas pistas, pois, servindo-se de sua erudição espantosa, famosa à sua época, Schwob mistifica, faz passar o real pelo imaginário e o imaginário pelo real Freqüentemente visto como o escritor da dualidade e do enigma, nele conviviam o artista e o erudito, o homem de análise e o criador imaginativo.

$\mathrm{O}$ que era visto, por muitos em seu tempo, como um defeito, falta de originalidade ou talento ${ }^{1}$, esse eterno recriar, essa mistura entre o real e o imaginário, é o que, em nossos dias, o singulariza e faz de Schwob um autor profundamente moderno. É que a maneira como se lê Schwob modificou-se com os anos. Ele é, hoje, mais do que um simbolista ou decadente fin de siècle. Sua obra ajuda-nos a pensar a literatura, na medida em que traz em si questões fundamentais, como os limites entre realidade e ficção, as polifonias narrativas, o leitor/autor. Nas palavras de Christian Berg e Yves Vadé (2002, p. 7), Schwob transformou "de manière décisive notre manière de penser la littérature".

Schwob recusava o naturalismo que, segundo ele, havia banido da literatura a imaginação e reduzido esta arte a uma estéril enumeração de detalhes. O romance, gênero naturalista por excelência, encarnação da estética realista, é preterido pelo autor em favor de narrativas curtas. Assim, nenhum romance, no sentido tradicional do termo, integra a obra de Schwob, que prefere o conto, 
a novela ou, ainda, fragmentos de prosa poética. Reagrupadas segundo um sentido de unidade, geralmente dado e explicado em seus prefácios, tais narrativas compõem o que o autor denominou de romance impressionista, gênero precursor de um tipo de narrativa que vai se desenvolver no século XX. Um romance que "n'est plus une leçon complète mais une énigme, quelque chose d'inattendu qui ne reflète pas cette construction linéaire à laquelle on nous avait habitués" (Guerrero, 2004, p. 47).

O maravilhoso e todas as suas manifestações - mitologias, maravilhoso cristão, contos de fadas e lendas populares - são o objeto de predileção da escrita de Schwob. São seres e acontecimentos sobrenaturais que cruzam o mundo ordinário e seus atores. São viagens e utopias que deslocam, alienam. Em seu gosto por tratar dos comportamentos extremos e mistérios do inconsciente, Schwob pressagia o advento da psicanálise, o que faz dele um escritor à frente de seu tempo, precursor não apenas dos surrealistas, como é costume lembrar, ou de Jorge Luis Borges, como é obrigatório referir, mas de todos os que, depois, fazem da leitura esse lugar do desconhecido.

Temas incomuns, formas inovadoras. Monelle, a certa altura do percurso iniciático, ao longo do qual ela conduz o narrador, naquela planície fora do tempo e do espaço onde se dá seu encontro, afirma que "[...] toute construction est faite de débris, et rien n'est nouveau em ce monde que les formes" (Schwob, 2002, p. 400). Esta é uma das concepções centrais de Schwob acerca da literatura. Tudo já foi dito e esquecido, nada há para ser criado, o artista é, então, aquele que traz a forma nova, para dizer a mesma coisa. Escrever bem, segundo Schwob, era a única coisa que restava à sua geração, pois "le style est la seule chose qu'un artiste peut apporter à l'art” (Guerrero, 2004, p. 50).

Dentre as muitas especificidades dessa escrita preciosa a que poderíamos chamar de 'estilo Schwob' a palavra ocupa um lugar central. É através de um trabalho cuidadoso sobre o léxico que Schwob constrói sua prosa poética inusitada. São cores e aromas, 
atmosferas de épocas passadas e fora do tempo que nos vêm através de palavras raras, justapostas a adjetivos absolutamente ordinários, combinações inesperadas num estilo influenciado pela pintura e também pela música. Da pintura, a riqueza do detalhe, a importância da sinestesia visual. Schwob falava de "vue des mots". Da música, a sonoridade das palavras e o ritmo da frase. A passagem citada abaixo nos vem do Il libro della mia memória (Schwob, 2002, p. 964):

Lire Herrick, c'est lire des abeilles et du lait. Les mots sont luisants d'huile de fleurs, frottés de nard et diaprés de gouttelettes parfumées. Ses vers volent à l'éternité avec de petites ailes d'or battu. Il ne faut pas plus qu'ouvrir les Hespérides et y tremper vite les yeux comme dans une vapeur de benjoin. Toute ligne apparue est peinte d'odeur qu'on hume du regard.

Qual o desafio em se traduzir, hoje, esta obra cuja singularidade e contemporaneidade, de formas e temas, ainda interroga a literatura? Nas traduções realizadas em português brasileiro, três de A cruzada das crianças e uma de Vidas imaginárias, em que medida Schwob nos é dado, e como? A primeira tradução de $A$ cruzada das crianças data de 1988, por Milton Hatoum. Dorothée de Bruchard nos propõe uma nova tradução da mesma obra oito anos depois, em 1996. Um ano depois, Vidas imaginárias é traduzido por Duda Mendonça. Em 2007 surge uma terceira tradução de $A$ cruzada das crianças, por Celina Portocarrero.

O cenário das traduções de Schwob no Brasil não é vasto, duas obras apenas, o que certamente contribui para que ele se mantenha como o ilustre desconhecido que é. Situação que é a mesma, guardadas devidamente as proporções, em seu próprio país: autor quase desconhecido ou autor para poucos, tão admirado quanto secreto. Além disso, as traduções ao português brasileiro parecem obedecer muito mais a um esforço individual, ou gosto pessoal, de um 
tradutor ou editor específico, o que não é raro no universo da tradução literária no Brasil, do que a um esforço concertado ou a um inusitado 'momento Schwob' nos meios editoriais. Isso explicaria, talvez, as três traduções de $A$ cruzada das crianças, obra preferida de muitos de seus raros leitores?

Traduções que cumprem projetos tradutivos distintos, vale salientar. As duas primeiras, de Milton Hatoum e Dorothée de Bruchard, em edições bilíngües, trazem o prólogo que Borges escreveu para a tradução espanhola em 1949. A primeira delas, editada pela Iluminuras, apresenta ainda, em fim de volume, um sumário cronológico da vida do autor. A tradução de Dorothée de Bruchard, editada pela Paraula, mostra uma edição apurada, com ilustrações e elementos gráficos que remetem ao período medieval, época na qual a narrativa se desenrola. Dois detalhes ainda importantes: a própria tradutora é a editora e o texto em francês aparece face ao texto em português, permitindo uma confrontação direta e constante da tradução e seu original. É fácil observar que ambas as traduções seguem um desejo maior, que é o de apresentar Schwob ao público brasileiro, de maneira cuidada, em edições que deixam entrever a importância do autor que introduzem.

A última tradução de $A$ cruzada das crianças, datando de 2007, editada pela Nova Fronteira, aparece num volume intitulado $O s$ melhores contos que a História escreveu, organizado por Flávio Moreira da Costa. Ali, Schwob avizinha outros tantos contistas, de várias nacionalidades, visto tratar-se de uma antologia. Interessante notar que outro texto de Schwob participa da coletânea, 'O capitão Kid', que, originalmente, faz parte das narrativas que integram Vidas imaginárias. Ainda digno de nota é o fato de que, no pequeno prólogo que introduz $A$ cruzada das crianças, informa-se que ali não figura o texto completo, mas apenas um trecho, o que não é verdade, pois as oito narrativas que compõem a obra são apresentadas na íntegra.

Vidas imaginárias, traduzido por Duda Machado em 1997, mereceu, também, uma edição bem planejada. O livro conta, em suas 
páginas finais, com um pequeno texto, de autoria do tradutor, apresentando Schwob a seu novo público. O próprio tradutor dirige a coleção onde o volume aparece, a qual, segundo suas próprias palavras, "procura oferecer ao leitor um conjunto de livros capaz de ampliar e enriquecer suas escolhas pessoais nos domínios da criação literária, do ensaio e da filosofia" (Machado, 1997). A coleção elege "pequenas ou grandes obras-primas ainda desconhecidas ou pouco divulgadas [...]" (id.). A edição conta ainda com algumas poucas linhas de Borges, sobre Schwob e suas Vidas imaginárias, à guisa de apresentação.

São muitas as possibilidades de aproximação de uma tradução, o exercício normativo, do julgamento, tradicionalmente muito presente, ou mesmo da comparação entre traduções de uma mesma obra, não nos deterá aqui. Como nos lembra Borges em suas Versiones Homéricas, "el concepto de texto definitivo no corresponde sino a la religión o al cansancio". Interessa-nos algo mais, precisamente o que ao tradutor interroga e desafia, sendo muito provavelmente esse o lugar no qual o autor se mostra em sua particularidade ou sugere seu mistério.

E os desafios em Schwob são muitos. Sua prosa altamente poética abunda em assonâncias, sua pontuação é irregular, pois não serve ao sentido, mas à música. E muito mais. Cria atmosferas, caracteriza personagens, imprime emoções. Ora inimigo de vírgulas que quebram o ritmo e compartimentam a frase, ora entrecortando sua prosa de inúmeros pontos finais e parágrafos minúsculos, Schwob escreve como um músico compõe. O ritmo ali é mestre. Atentar para a pontuação irregular, não conforme a certa idéia de ordem do discurso, ler esta pontuação como elemento formador do texto, que ela é, é resistir torná-la aceitável e regrada. Tudo isso lembra o tradutor e teórico Antoine Berman (1999) que aponta como uma tendência da prática canônica da tradução este querer tornar mais claro, conforme a regras que, segundo Henri Meschonnic (1973), nada tem que ver com a literatura, mas com, para usar seus próprios termos polêmicos, o que ele 
chama de 'estetização' da literatura. Berman fala em 'racionalizar', qual seja, recompor segundo certa idéia de discurso ordenado.

Voltando a Schwob, o trabalho sobre o léxico é outro de seus lugares de eleição para a composição. Combinações inusitadas de substantivos e seus epítetos, palavras raras, retornos eruditos à filologia, construção de sistemas significantes que remetem a universos específicos: da infância (todas as palavras e sufixos da pequenez), das cores (o branco, o vermelho, o dourado, o preto e seus inúmeros matizes), dos lugares míticos e iniciáticos (o jardim, a floresta, o deserto). O texto de Schwob é uma tela, então, onde as palavras são cores insubstituíveis que se remetem, infinitamente, umas às outras. Nada ali pode ser deixado ao acaso, ou ao descuido. Assim como a música, a pintura influencia profundamente seu texto. Artes que ele comparava insistentemente à literatura. $\mathrm{O}$ tradutor de $A$ cruzada das crianças, por exemplo, não pode perder o jogo riquíssimo de cores que perpassa muitos dos oitos contos que a compõem. É uma profusão de brancos e vermelhos, além de dourados, desdobrados por inúmeras palavras que a essas matrizes remetem (Schwob, 2002, p. 477-503):

Jamais il y a eu tant de fleurs blanches et roses. Les prairies sont fraîchement lavées. Partout le sang de Notre-Seigneur étincelle sur les haies. Notre-Seigneur est couleur de lys, mais son sang est vermeil.

L'or des parois de cette cellule est usé par le temps. Elles sont blanches. Le cercle de ton soleil est blanc. Ma robe est blanche aussi, et mon coeur desséché est pur.

Je ne peux plus marcher, parce que nous sommes dans un pays brûlant, ou deux méchants hommes de Marseille nous ont emmenés. Et d'abord nous avons été secoués sur la mer dans un petit jour noir, au milieux des feux du ciel. 
Em Vidas imaginárias, a elipse na estrutura narrativa, que se manifesta em um não dizer, em uma suspensão da informação apenas sugerida, na enumeração de dados banais, ecoa na estrutura sintática, através de parataxes que se sucedem e desafiam, por vezes, a concepção clássica de texto bem construído, ponto essencial de reflexão para a tradução literária. Schwob recusa, em suas Vidas imaginárias, a intriga cronológica do romance tradicional, é como se ele tirasse do leitor o fio condutor da compreensão para melhor abrir-lhe os espaços intersticiais da narrativa. Algumas passagens o exemplificam (Schwob, 2002, p. 522-538):

La mère d'Hérostratos était violente et orgueilleuse. On ne sut point quel était son père. Herostratos déclara plus tard qu'il était fils du feu. Son corps était marqué, sous le sein gauche, d'un croissant, qui parut s'enflammer lorsqu'on le tortura. Celles qui assistèrent sa naissance prédirent qu'il était assujetti à Artemis.

Le mari Metellus leur semblait odieux. Sa femme résolut de s'en débarrasser. Un jour qu'il revenait du Sénat, lassé, elle lui présenta à boire. Metellus tomba mort dans l'atrium.

Por meio de litotes, parataxes e elipses, Schwob acena com o que, para ele, era uma convicção estética e, mesmo, filosófica: a continuidade não existe. Como bem sublinha Dominique Rabaté (2002, p. 187), aos mecanismos tradicionais do romance - saturação de causalidades, ligações, continuidade - Schwob opõe a interrupção, a narrativa seca, frases curtas que se sucedem sem passagem harmoniosa entre elas.

Estes são certamente aspectos importantes que vão interpelar o tradutor de Marcel Schwob. Outros, a que não referimos, são tanto ou mais desafiantes. As obras já traduzidas ao português podem elucidar outros, mais especificamente ligados à sintaxe da língua. É, enfim, um vasto campo inexplorado de pesquisa, leitura, dúvida 
e deleite, pois que, na aventura de traduzir ou estudar as traduções de Schwob, não há como não passar por estes caminhos.

\section{Nota}

1. "C'est de la fabrication, de la marqueterie, et je sens comment c'est fait et avec quoi. De vastes lectures, dans tous les genres (...) au fond, tout cela sent les vieux livres" (Paul Léautaud, 1959, apud Agnès Lhermite, 2002, p. 12).

\section{Bibliografia}

BERG, Christian; VADÉ, Yves. Marcel Schwob d'hier et d'aujourd'hui. Paris: Champ Vallon, 2002.

BERMAN, Antoine. La traduction et la lettre ou l'auberge du lointain. Paris: Seuil, 1999.

BORGES, Jorge Luis. "Las versiones homéricas". In: . Obras Completas

- 1923-1972. Buenos Aires: Emecé, 1974.

FABRE, Bruno. Marcel Schwob et les écrivains de son temps. In: Europe Revue Littéraire Mensuelle, Paris, n. 925, p. 65-77, 2006.

GENETTE, Gérard. Palimpsestes - La littérature au second degré. Paris: Seuil, 1982. 
GOUDEMARE, Sylvain. Marcel Schwob ou les vies imaginaires. Paris: Le Cherche Midi Éditeur, 2000.

GUERRERO, Maria José Hernandéz. Marcel Schwob cent ans après. In: Thélème, Revista Complutense de Estudios Franceses, Madrid, Universidade Complutense de Madrid, v. 19, p. 45-55, 2004.

LHERMITTE, Agnès. Palimpseste et Merveilleux dans l'œuvre de Marcel Schwob. Paris: Honoré Champion, 2002.

MESCHONNIC, Henri. Pour la poétique II. Paris: Gallimard, 1973.

RABATÉ, Dominique. Vies imaginaires et vies minuscules: Marcel Schwob et le romanesque sans roman. In: Christian BERG ; Yves. VADÉ. Marcel Schwob d'hier et d'aujourd'hui. Paris: Champ Vallon, p. 177- 191, 2002.

REGNIER, Thomas. Qui a peur de Marcel Schwob. In: Europe Revue Littéraire Mensuelle, Paris, n. 925, p. 23-31, 2006.

SCHWOB, Marcel. A cruzada das crianças. Tradução de Milton Hatoum. São Paulo: Iluminuras, 1987.

. A cruzada das crianças. Tradução de Dorothée de Bruchard. Porto Alegre: Paraula, 1996. 1997.

. Vidas imaginárias. Tradução de Duda Machado. São Paulo: Editora 34,

. Oeuvres. Paris: Les Belles Lettres, 2002.

. Oeuvres. Paris: Phébus, 2002.

. A cruzada das crianças. Tradução de Celina Portocarrero. In: Flavio Moreira da Costa. Os melhores contos que a História escreveu. São Paulo: Nova Fronteira, 2007, p. 137-152. 